\title{
Recent NASA Wake-Vortex Flight Tests, Flow-Physics Database and Wake-Development Analysis
}

\author{
Dan D. Vicroy \\ NASA Langley Research Center
}

\author{
Paul M. Vijgen, Heidi M. Reimer, Joey L. Gallegos and Philippe R. Spalart
}

Boeing Commercial Airplane Group

This paper is declared a work of the U.S. Government and is not subject to copyright protection in the United States.

\begin{abstract}
A series of flight tests over the ocean of a four engine turboprop airplane in the cruise configuration have provided a data set for improved understanding of wake vortex physics and atmospheric interaction. An integrated database has been compiled for wake-characterization and validation of wake-vortex computational models. This paper describes the wake-vortex flight tests, the data processing, the database development and access, and results obtained from preliminary wake-characterization analysis using the data sets.
\end{abstract}

\section{INTRODUCTION}

Several of today's major airports are operating near their capacity limit, leading to an increase in airport congestion and delays. The ability to relieve the congestion through airport expansion or new airport construction is limited and increasingly difficult. NASA, the Federal Aviation Administration (FAA), airport operators, the aircraft industry and the airlines are all interested in methods to improve airport capacity. NASA is conducting a Terminal Area Productivity (TAP) Program with the goal of providing the necessary research to support the FAA and industry in safely achieving clear-weather (visual flight rules) airport capacity in instrument meteorological conditions (IMC). The flight test described in this paper is part of the Reduced Spacing Operations element of the TAP Program [1].

The spacing required to avoid the wake turbulence of the preceding airplane is one of the limiting factors in safely reducing in-trail spacing. A wake vortex upset is most hazardous for aircraft near the ground during landing and takeoff. The degree of upset mainly depends on the relative size of the vortex generating and vortex encountering airplanes and the extent of wake decay. In addition to the spacing between commercial aircraft, some elements of paratrooper airdrop procedures are also limited by location and strength of trailing vortices from preceding aircraft [2]. The strength of the encountered wake is highly dependent on the atmospheric state (e.g. stratification, wind magnitude and direction, ambient turbulence) $[3,4]$.

Numerous laboratory experiments and analytical models have been developed to study and simulate wake vortex flow physics. (Reference 3 provides a recent overview of wake-vortex flow physics issues and understanding.) However, there is very little full-scale data available for comparison with and validation of the experimental and computational results. Many of the previous wake-measurement flight tests have obtained only qualitative or limited quantitative data on the atmospheric state, which can have a direct influence on wake-flow physics. The flight test data described in this paper are an attempt to develop a wake measurement data set with the accompanying atmospheric state information. This data set has been compiled into a database that can be used by wake vortex researchers to compare with experimental and computational results. This paper provides an overview of the wake-measurement flight tests and the database development and access. In addition, preliminary wakecharacterization results obtained with the data set are presented.

\section{WAKE-MEASUREMENT FLIGHT TESTS}

The objective of the flight tests was to develop a full-scale wake measurement test method to obtain a detailed wake-development data set with the accompanying atmospheric state information, as discussed in the introduction. The tests used two NASA airplanes as illustrated in figure 1.

The NASA-Wallops Flight Facility's Lockheed-Martin C-130, shown in figure 2, was the wake generator. It was outfitted with wing tip smokers to mark the wake. It weighed between 95,000 and 113,000 pounds during the test with a geometric wingspan of 132 feet 7 inches. The tests were all flown with the C-130 in the "clean" configuration (i.e. flaps up and gear retracted), resulting in a trailing wake with a single vortex pair representative of a transport aircraft during climb-out, cruise or initial approach. The tests were conducted over the ocean along the eastern shore of Virginia. 


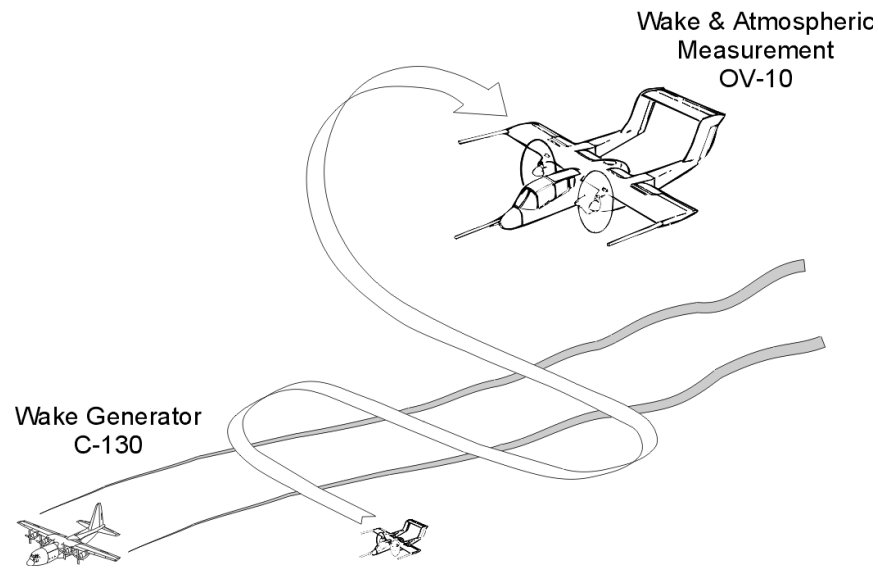

Figure 1. Wake measurement flight test setup.

The NASA-Langley North-American Rockwell OV-10A measured the wake and atmospheric conditions. The OV-10 was equipped with a three-boom, flow-sensor arrangement to measure the flow-field characteristics of the wake. The booms were located on each wing tip and the right side of the nose as shown in figure 3 . As is customary, the booms were designed to place sensors as far ahead of the aircraft as possible yet have sufficient stiffness and low mass (high natural frequency) to prevent unwanted vibration influence on the sensor measurements. Standard NACA pitot-static probes with balsa angle-of-attack and sideslip vanes were mounted at the end of each wingtip. A 5-hole pressure probe was mounted at the end of the nose boom to provide flow direction, airspeed and static pressure measurements. Wind-tunnel calibrations have been obtained for the three probes and airspeed calibration flights have been conducted to correct the probes for residual airframeinduced flow perturbations.

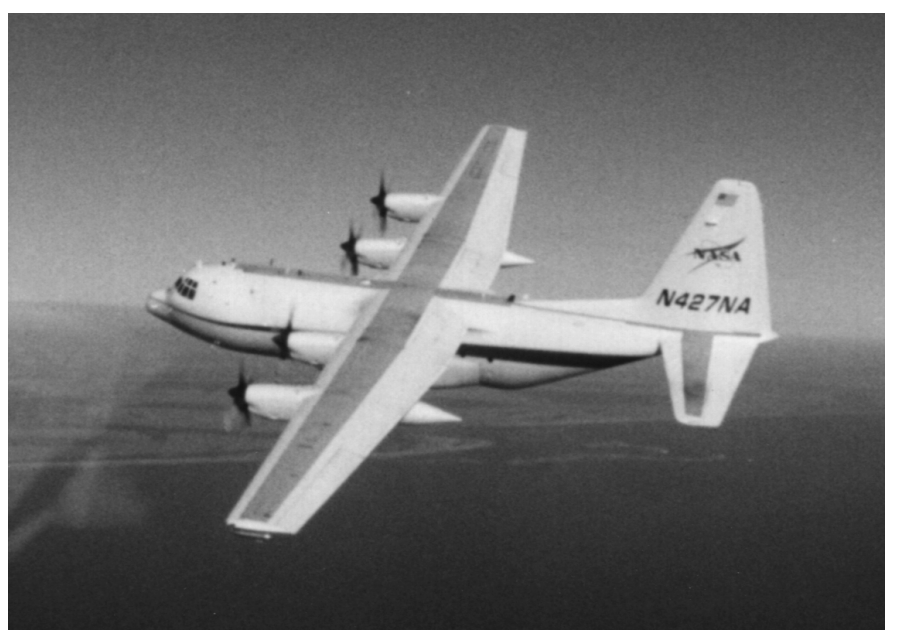

Figure 2. C-130 wake generator airplane.

The OV-10 flew through the wake at various downstream distances measuring its velocities and position. A picture of a wake measurement taken from the video camera mounted on the left tail of the OV-10 (as noted in figure 3) is shown in figure 4 . The smoke clearly denotes the vortex pair in the C-130 trailing wake. Some perturbation of the wake as a function of distance can be seen in the image.

The OV-10 was also equipped to measure the ambient weather conditions for correlation with the wake transport and decay characteristics. Temperature, pressure and humidity measurements are continuously recorded to complement available ground-station weather balloon data, while the local wind velocities are derived from the onboard inertial and GPS based navigation systems. An extensive overview of research instrumentation and measurement capabilities of the OV-10 is presented in reference 5 .

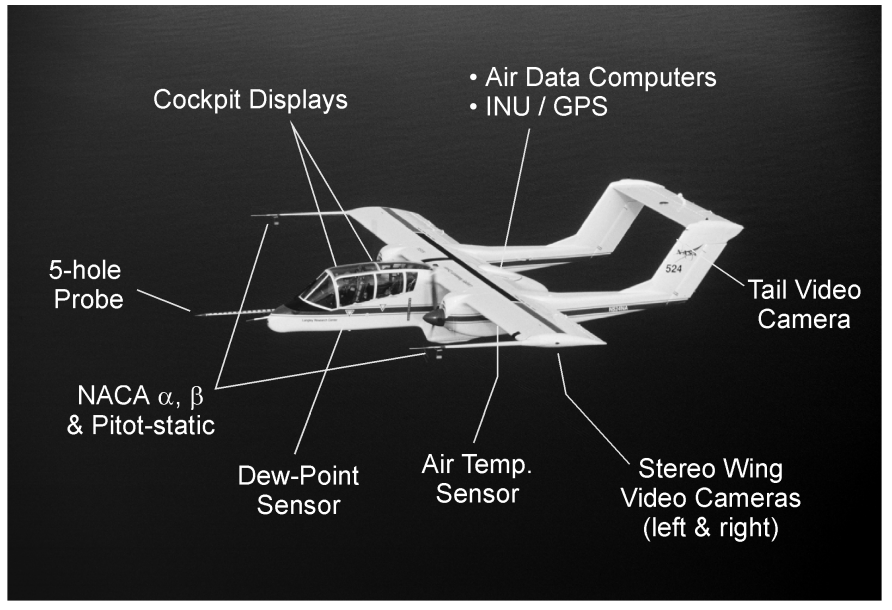

Figure 3. OV-10 major instrumentation systems

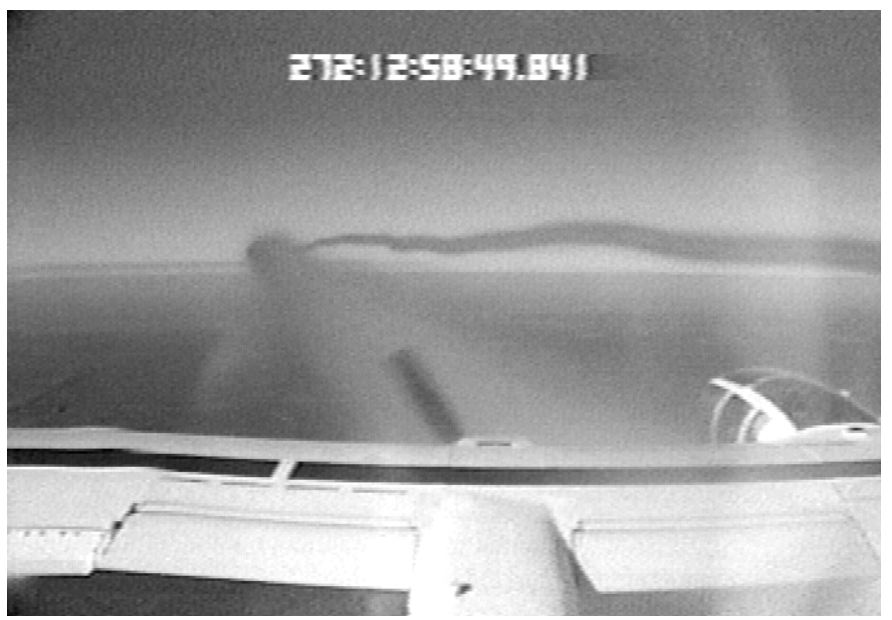

Figure 4. OV-10 tail video of wake $2.4 \mathrm{nmi}$ in trail.

The general flight test procedure was as follows. The OV-10 would fly to the flight test area and begin a series of "weather" runs. These would begin with one or two "turbulence" runs, which were 2-minute, level, constant heading flight segments 1000 feet below the test altitude. The test altitude was generally 4000 or 5000 feet. This was followed by a "weather profile" run, which was a constant speed, constant heading climb from 1000 feet below to 500 feet above the test altitude. Another series of turbulence runs would then follow 500 feet above the test altitude. After completing the weather runs, the OV-10 would rendezvous with the $\mathrm{C}-130$ and start a series of "wake measurement" runs. The C-130 would fly 
a constant speed and heading at the test altitude. The OV-10 measured the wake by flying slower than the C-130 and making a series of wake penetrations at increasing ranges behind the $\mathrm{C}-130$. At the conclusion of a series of wake measurement runs an additional series of weather runs were then conducted. Although the OV10 made measurements over the entire length of the wake visualized by smoke, the measurements do not constitute a 'frozen wake'. In other words, the measurements at increasing distance behind the generator aircraft are made in different parts of the atmosphere. (As an example, the OV-10 travels about $30 \mathrm{nmi}$ during an encounter run that spans $9 \mathrm{nmi}$ of trailing wake.)

The ideal data set for wake development and decay analysis would be a series of instantaneous, 3-dimensional wake measurements within a fixed air mass at multiple streamwise distances, from initial wake roll-up until final decay or breakup. However, there currently is no practical test method or instrumentation system to make such a global measurement.

\section{FLIGHT DATA REDUCTION PROCESS}

The data flow of the flight-data reduction process is shown in figure 5 . For each flight the OV-10 generates four data products:
- Time-tagged, VHS video recordings from the tail camera and both wing-tip cameras.

- Flight notes from the test pilot and flight engineers of event times and conditions

- Time-tagged data tape from the experimental data system

- Time-tagged Ashtech differential Global Positioning System (GPS) data

The flight notes and video data are reviewed and used to establish a precise log of event times and test conditions called the "flight event" file. This information is then used to extract the pre- and post-flight instrument calibration data and the data for the calibration check flight maneuvers. This calibration data is used to establish the instrumentation zero bias values, which are saved as a "flight constants" file for each flight. The event and constants files and the data from the onboard data acquisition system (DAS) are input for the OV-10 Data Reduction and Analysis Program (OVDRA). This program applies the instrument calibration and bias corrections to the DAS data and computes the inertial referenced wind components. The output of OVDRA is a calibrated data file for each run of the test flight. These run data files are used to compute turbulence levels and generate wind and temperature profiles.

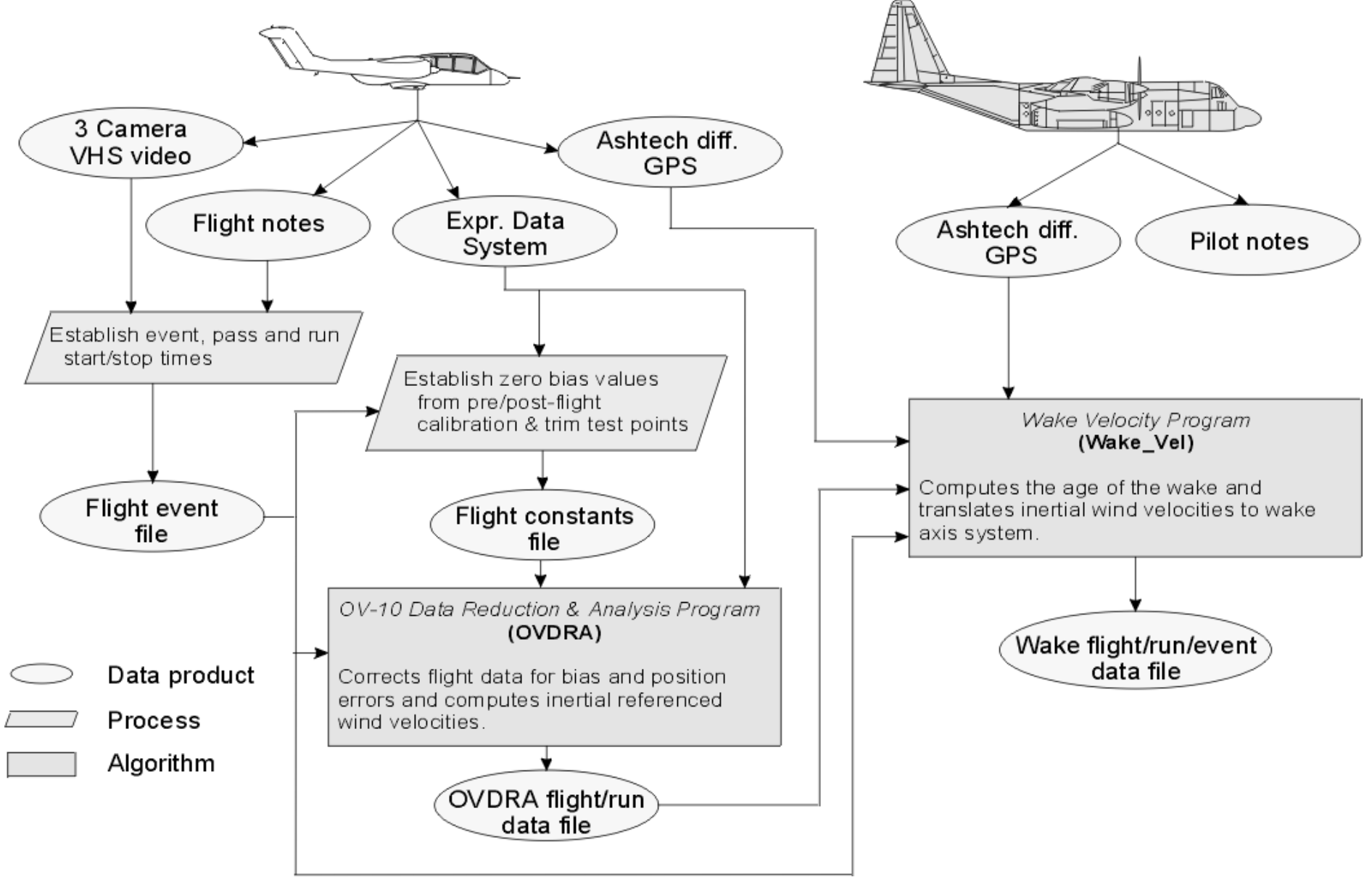

Figure 5. Flight data reduction process. 


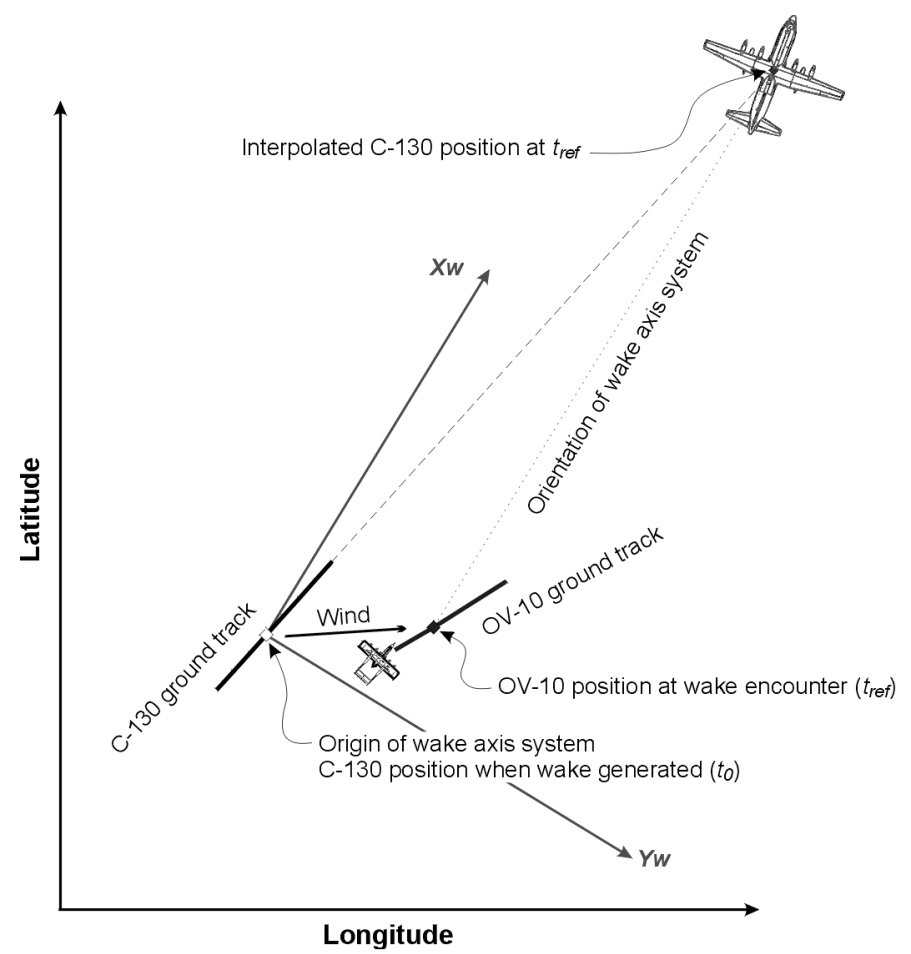

Figure 6. Wake axis system.

The OV-10 and C-130 inertial positions are known from differential GPS measurements collected at $1 \mathrm{~Hz}$. The Wake_Vel program (fig. 5) uses this position information and the OVDRA output to translate the measured wake velocity data to an inertial-referenced wake axis system.

The wake axis system, shown in figure 6 , is aligned with the heading between the OV-10 and C-130 at the time of the wake vortex encounter $\left(t_{r e f}\right)$. The origin of the coordinate system ( $\mathrm{C}-130$ position at $\left.t_{o}\right)$ is the $\mathrm{C}-130$ position when it generated the wake being measured at $t_{r e f}$.

The wake velocity algorithm Wake_Vel translates the OVDRA wind measurements to the wake coordinate system. Each wake measurement event has it own wake coordinate system. Since the wake translates with the airmass the wake origin location must be iteratively determined based on the known C-130 track and OV-10 measurement location, and an assumed average wind component. The wake-origin location also determines the wake age. The wakes translation with the wind also requires that the wake measurement positions be corrected to account for the drift of the wake over the measurement period.

The OV-10 could measure the wake velocity at 3-points in space at any instant in time. A wake measurement pass consists of 3 streams of wake velocity data collected at $128 \mathrm{~Hz}$, over a 5 to 10 second period (i.e. about 600 to 1000 data samples are taken). An example of a wake velocity measurement from the three booms is shown in figures 7 and 8 . These figures show the horizontal and vertical profiles of the wake measurement pass along with the wake velocity vectors. The figures show that during this particular wake measurement the
OV-10 was flying through the wake from left to right. The airplane flew through the left vortex but passed below the right vortex. Each boom traces a different path in space, which is clearly seen as the airplane banks about 35 degrees left at the end of the measurement pass (fig. 8).

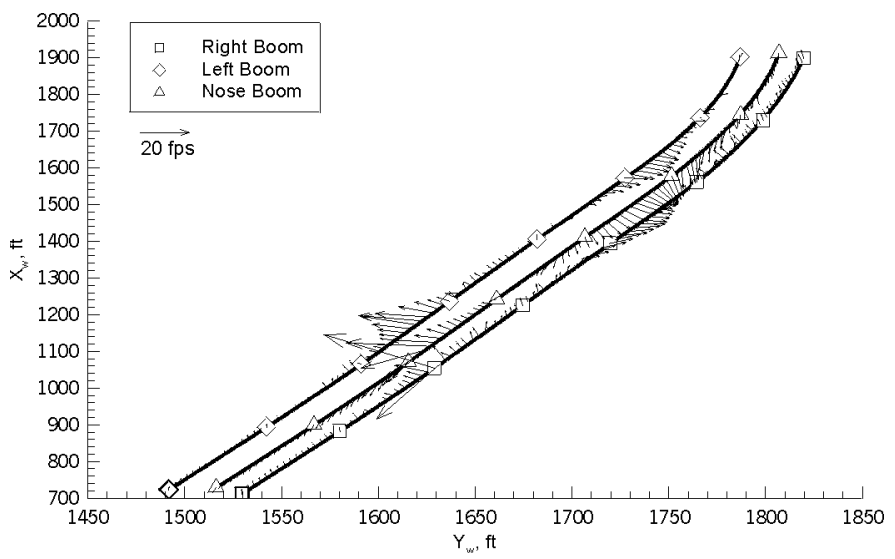

Figure 7. Horizontal profile of OV-10 wake measurement pass (Flight 558, Run 26, Event 1).

The pilot notes from the C-130 provide weight and test condition information used to estimate the initial circulation strength of the wake for comparison with circulation derived from the wake measurements.

NONDIMENSIONALIZATION - Several of the data values are nondimensionalized for comparison with other data sets. The nondimensionalization parameters are defined as follows:

The length scale is the initial spacing between vortices based on an elliptical span load.

$$
b_{*}=\frac{\pi}{4} b
$$

For the C-130 $b_{*}$ is 104 feet.

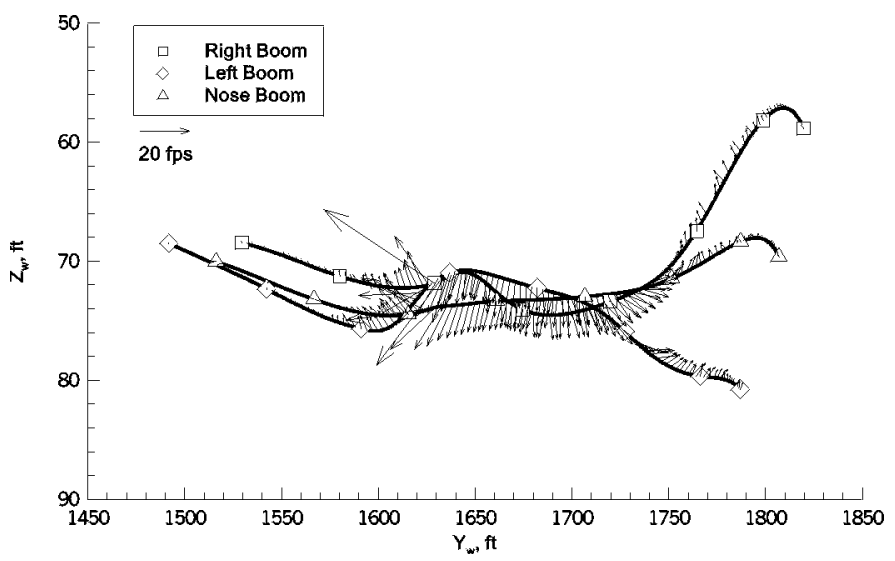

Figure 8. Vertical profile of OV-10 wake measurement pass (Flight 558, Run 26, Event 1).

The initial circulation is computed as:

$$
\Gamma_{*}=\frac{W}{b_{*} \rho V_{t}}
$$


The initial wake descent velocity is computed as:

$$
V_{*}=\frac{\Gamma_{*}}{2 \pi b_{*}}
$$

The time scale is the time for the wake to descend one length scale.

$$
t_{*}=\frac{b_{*}}{V_{*}}
$$

The nondimensionalization values derived from some of the flight-test results discussed later in this report are listed in table 1.

Table 1. Nondimensionalization parameter values.

\begin{tabular}{|c|c|c|c|c|}
\hline Flight & Run & $\begin{array}{c}\Gamma_{*} \\
\mathbf{f t}^{\mathbf{2}} / \mathbf{s}\end{array}$ & $\begin{array}{c}V_{*} \\
\mathbf{f t} / \mathbf{s}\end{array}$ & $\begin{array}{c}t_{*} \\
\mathbf{s e c}\end{array}$ \\
\hline 558 & 26 & 1706 & 2.6 & 39.8 \\
\hline 705 & 27 & 2123 & 3.2 & 32.0 \\
\hline 705 & 28 & 2206 & 3.4 & 30.8 \\
\hline 705 & 29 & 1482 & 2.3 & 45.8 \\
\hline 705 & 30 & 1464 & 2.2 & 46.4 \\
\hline 705 & 37 & 2033 & 3.1 & 33.4 \\
\hline
\end{tabular}

\section{DATA BASE}

The flight test data obtained from seven flights conducted in 1995 and 1997 have been compiled into an organized structured database that may be used by researchers for detailed wake vortex analysis. The main purpose of the database is the integration of all relevant flight data into an organized and structured data set.

The data set includes relevant (dimensional and nondimensional) measured and reduced OV-10 and C-130 parameters used to determine the wake velocities and location from the wake measurement runs, as well as weather parameters obtained during the measurement runs and dedicated weather runs. A total of nearly 200 parameters are included in the data set, with some redundant measurements retained to allow comparison of instrumentation systems. Selected parameters are nondimensionalized for comparison between runs at different speeds of the generator aircraft and for comparison with other experimental results. The database also includes weather balloon data and captured frames from the OV-10 tail camera video images (such as shown in figure 4).

The database is comprised of several different data categories. Four categories are centered on the OV-10 measurements:

- Main Run Data Type: Data is included at $32 \mathrm{~Hz}$ rate covering the duration of each OV-10 run. This file type would be used for wake location analysis.
- Encounter Data Type: Data at $128 \mathrm{~Hz}$ that covers the duration of an individual OV-10 wake measurement pass. This file type contains wake-velocity data as shown in figures 7 and 8 , in addition to other parameters that may be used for wake profile analysis. The Main-Run data set includes references to the occurrence of wake measurement passes.

- Weather Run Data Type: Data that cover the duration of a weather run is included at a rate of $128 \mathrm{~Hz}$. A reduced set of parameters for analysis of turbulence and atmospheric state is retained.

- Wake Video Data Type: Digital image files captured from the OV-10 tail camera are included for many encounters. These images can be used towards characterization of the wake shape. The Main-Run data set includes reference to the availability of the video images.

In addition to data related to the OV-10 measurement systems, additional data sets are provided:

- Weather data: Available vertical weather profile data obtained from standard weather balloons are included as a separate data category in the database.

- Encounter-event Descriptions: Detailed OV-10 flightlog description files are included that serve as overviews of the OV-10 flight profiles and provide some encounter characterization.

- Wake velocity plots: Processed wake-encounter velocity profiles (such as shown in figures 7,8 and $16 \mathrm{a})$ are included to assist the user in familiarization with the data quality.

- Data-reduction documentation: Source code used to reduce the OV-10 flight measurements to wake-profile velocity data are provided.

- Instrumentation documentation: Pertinent information about sensors and instrumentation systems installed on the OV-10 aircraft are included (see also Ref. 5).

Figure 9 summarizes the flight-data categories described above. A summary of the data contained from each of the seven flights is provided in Table 2 . The presently ASCIIformatted database can be used as stand-alone database. The user would extract desired data using time as independent parameter from the data base and port the set to his own data-analysis routines. Alternately, the user could load the integrated data set into a suitable relational database for searching and post processing. The high data rates used in Main-Run and Weather-Run categories together with the approximately 200 encounters obviously result in a rather large database. However, detailed spatial information is now preserved for wake encounter and atmospheric-turbulence analysis. 


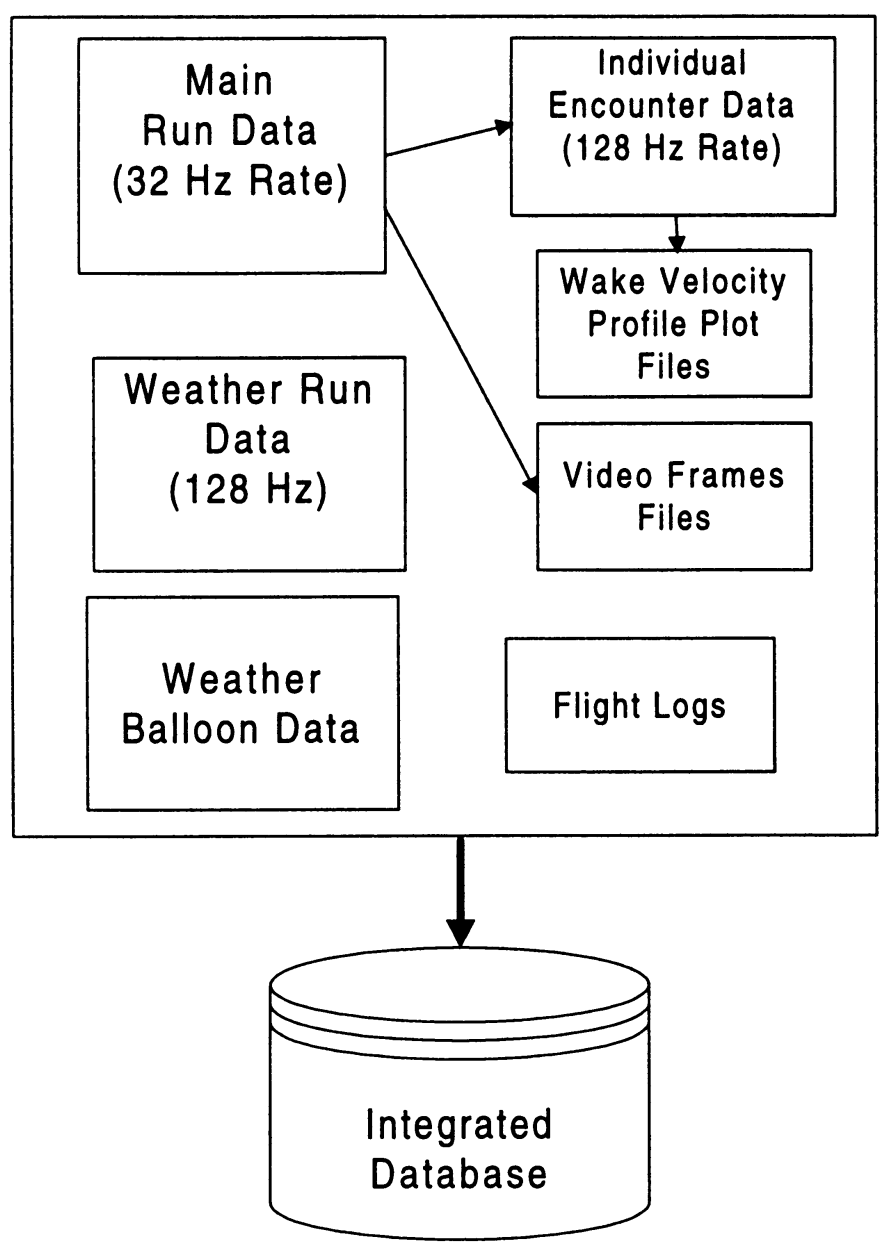

Figure 9. Database components and structure.

The database contained on optical disks can be obtained by contacting the first author at: NASA Langley Research Center, MS 153, 100 NASA Road, Hampton, VA 23681-2199.

Table 2. Summary of database content.

\begin{tabular}{|c|c|c|c|c|}
\hline $\begin{array}{c}\text { Flight } \\
\text { Number }\end{array}$ & $\begin{array}{c}\text { Encounter } \\
\text { Runs }\end{array}$ & $\begin{array}{c}\text { Individual } \\
\text { Encounters }\end{array}$ & $\begin{array}{c}\text { Weather } \\
\text { Runs }\end{array}$ & $\begin{array}{c}\text { Wake } \\
\text { Images }\end{array}$ \\
\hline 556 & 9 & 49 & 2 & 37 \\
\hline 557 & 4 & 21 & 2 & 16 \\
\hline 558 & 6 & 42 & 2 & 6 \\
\hline 559 & 4 & 24 & 1 & 11 \\
\hline 560 & 4 & 8 & 2 & 9 \\
\hline 561 & 4 & 4 & 2 & 14 \\
\hline 705 & 4 & 84 & 4 & 0 \\
\hline Total & $\mathbf{3 5}$ & $\mathbf{2 3 2}$ & $\mathbf{1 5}$ & $\mathbf{9 4}$ \\
\hline
\end{tabular}

\section{PRELIMINARY WAKE CHARACTERIZATION}

Using the reduced OV-10 data contained in the database, preliminary results of wake and atmospheric characterization are presented. Results are given here as an illustration of the possible use of the available data for wake analysis. Detailed discussion of wake characterization is beyond the scope of this paper.
First, aspects of atmospheric conditions during the flights conducted are summarized with ambient turbulence levels quantified using different parameters. Next, wakedescent profiles, vortex velocity profiles and circulation development are illustrated.

AMBIENT ATMOSPHERIC CONDITIONS - The seven flights included in the database were conducted in three types of ambient atmospheric conditions (see Table 3 and Ref. 6). Some flights were conducted at altitudes near (cumulus) cloud layers, likely resulting in strong local variations in updraft and ambient atmospheric turbulence. Weather and overall wake development (shape) are summarized in Table 3. Measurements in the database should allow additional meteorological characterization (see also reference 6).

Flights 556, 557 and 558 were conducted in a nearly unstable stratified atmosphere (low Brunt-Vaisala frequency) with relatively high turbulent kinetic energy levels (to be discussed below). Flight 560, 561 and 705 were conducted in a rather stable atmosphere and in absence of clouds. Flight 559 had an intermediate level of stability.

AMBIENT TURBULENCE LEVELS - The OV-10 made dedicated "turbulence runs" of two minutes in length to gather data on the atmospheric turbulence in the area of the encounter runs. These "turbulence-run" data can be used to quantify variation in the atmospheric turbulence from one flight to another.

Ambient Turbulent Kinetic Energy - Turbulent kinetic energy $(T K E)$ is a measure to characterize atmospheric turbulence. TKE is determined from the $128 \mathrm{~Hz}$ measurements of the three wind velocity components $(u, v$, and $w)$ as follows:

$$
T K E=\frac{1}{2}\left(\sigma_{u}^{2}+\sigma_{v}^{2}+\sigma_{w}^{2}\right)
$$

where $\sigma_{\mathrm{u}}, \sigma_{\mathrm{v}}$ and $\sigma_{\mathrm{w}}$ are the standard deviations of the corresponding velocity components over some sample time. The range of TKEs obtained from the various "turbulence" runs in each flight is indicated in Table 3. Clearly, Flight 556 has overall much higher turbulence levels than Flight 705. A disadvantage of using TKE is the strong dependence of its magnitude on the duration of the measurement window used to evaluate equation 5 . To obtain measurements that include relatively large wavelengths (on order of the Crow mechanism) long sampling times (on order of 2 minutes) are needed. 

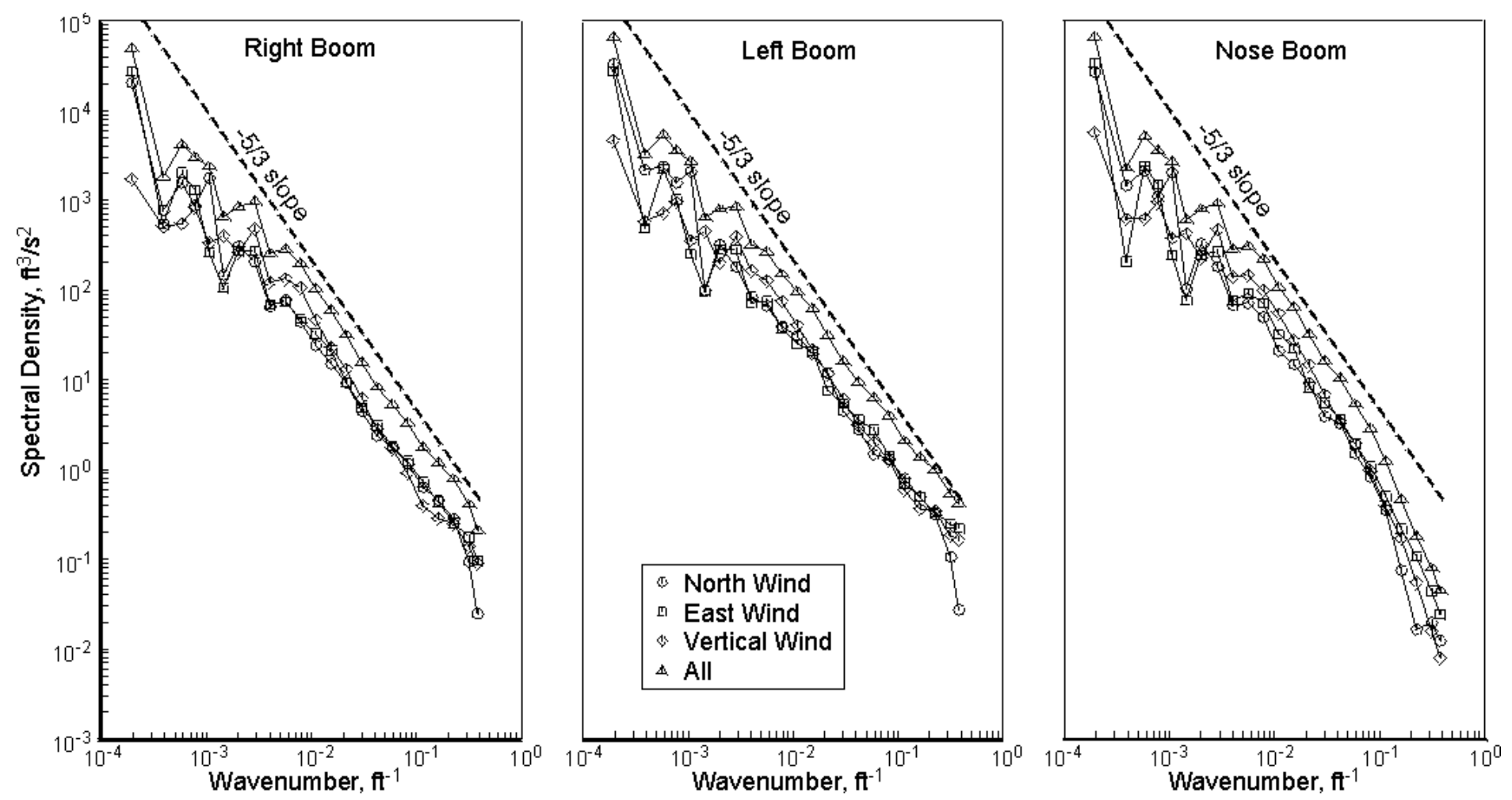

Figure 10. Spectral density from 2 minute "turbulence" run (Flight 556, Run 29).

Table 3. Summary of ambient atmospheric conditions

\begin{tabular}{|c|c|c|c|c|c|}
\hline $\begin{array}{l}\text { Flt. } \\
\text { No. }\end{array}$ & $\begin{array}{c}\text { Flight } \\
\text { Altitude } \\
\text { ft }\end{array}$ & $\begin{array}{l}\text { Weather } \\
\text { Summary }\end{array}$ & $\begin{array}{c}\text { TKE } \\
2 \text { min sample } \\
\mathrm{ft}^{2} / \mathrm{sec}^{2}\end{array}$ & $\begin{array}{c}\text { Brunt-Vaisala } \\
\text { frequency } \\
1 / \text { sec }\end{array}$ & $\begin{array}{l}\text { Wake Shape Summary } \\
\text { (Oscillation Amplitude) }\end{array}$ \\
\hline 556 & $2000-3400$ & Near cloud base, turbulent & $4.5-36$ & $(-0.00002)$ & $\begin{array}{l}\text { Large wake oscillations, bursting at } 2.5-4 \mathrm{~nm} \text {, and } \\
\text { Crow onset at }<1 \mathrm{~nm} \text {, linking later }\end{array}$ \\
\hline 557 & $2700-5200$ & Near cloud base, turbulent & $1.2-13$ & $0.0089-0.022$ & $\begin{array}{l}\text { Large wake oscillations, bursting at } 1.5-2.5 \mathrm{~nm} \text {, Crow } \\
\text { onset at } 1 \mathrm{~nm} \text {, linking later }\end{array}$ \\
\hline 558 & $4100-5700$ & High clouds & $1.1-1.2$ & $0.0055-0.0089$ & $\begin{array}{l}\text { Large wake oscillations, bursting at } 5 \mathrm{~nm} \text {, Crow onset } \\
\text { at } 1-2 \mathrm{~nm}\end{array}$ \\
\hline 559 & $\sim 5000$ & High clouds & $.98-7.3$ & $0.0077-0.01$ & Moderate wake oscillations \\
\hline 560 & $4000-5500$ & Clear sky & $.25-1.77$ & 0.017 & Small wake oscillations, \\
\hline 561 & $4000-5500$ & Clear sky & $0.3-1.9$ & 0.013 & Small wake oscillations \\
\hline 705 & $6200-8000$ & Hazy, low turbulence stable & $0.4-3.4$ & $0.01-0.015$ & Very small oscillations, Crow onset after $5 \mathrm{~nm}$ \\
\hline
\end{tabular}

Spectral Distribution of Ambient Turbulent Energy and Dissipation Rate - The "turbulence" run measurements were analyzed in the frequency domain using ensembleaveraged Fourier analysis.

As an example, spectral density results obtained from the 2-min. "turbulence" runs from Flights 556 and 705 are shown in Figs. 10 and 11, respectively. The power-spectral density is shown as function of the wavenumber for each wind components individually (for each boom), as well as combined (parameter labeled 'All'). The wave number is the frequency multiplied by $2 \pi / V_{t}$, where $V_{t}$ is the true airspeed of the OV-10. (The wave riumber is proportional to the inverse of the turbulent-eddy size.) In general, the measurements generally follow the "-5/3" slope predicted by Kolmogorov's theory for eddies in the inertial range of isotropic turbulence. The inertial range is resolved over a range of about 3 decades of wavenumber in these 2-minute data samples. The most-unstable wavelength of the Crow instability (at about $8.6 \cdot b_{*}$, see Ref. 13) occurs at a wave number of approximately 0.001 for the conditions in these plots, i.e. near the lower end of the resolved inertial range. The data in the inertial range from both samples show that small-scale atmospheric turbulence is isotropic, as expected. Similar levels and trends are obtained from each of the three OV-10 probes. Consistent with the TKE levels shown in Table 3, Flight 705 spectral energy densities are at much lower levels than in Flight 556, allowing measurement noise effects to become apparent, particularly at the highest wavenumbers. Nose-boom instrumentation resonance is visible in the low-turbulence data of Flight 705 . The highest wave numbers extend into a frequency range with instrumentation limitations (such as pneumatic lag for the nose-boom 
probe), obscuring the detection of the viscous range in the turbulence spectrum.

Table 4. Dissipation Rate and Turbulence Categories during "Turbulence Runs".

\begin{tabular}{||c|c|c||}
\hline $\begin{array}{c}\text { Flight } \\
\text { No. }\end{array}$ & $\begin{array}{c}\text { Range of } \\
\text { Turbulent } \\
\text { Dissipation Rate } \\
\mathbf{f t t}^{2} / \mathbf{s}^{\mathbf{3}} \text { ) }\end{array}$ & $\begin{array}{c}\text { MacCready Turbulence } \\
\text { Category [7] }\end{array}$ \\
\hline 556 & 0.01 & Moderate \\
\hline 557 & $0.01-0.04$ & Moderate \\
\hline 558 & $0.0002-0.001$ & Negligible/Light \\
\hline 559 & 0.0001 & Negligible \\
\hline 560 & 0.0001 & Negligible \\
\hline 705 & 0.00002 & Negligible \\
\hline
\end{tabular}

Besides the TKE, another indicator of atmospheric turbulence previously used to characterize flight-test data (e.g., Ref. 7) is the turbulent dissipation rate, which is a measure of the rate of dissipation of turbulent kinetic energy by action of viscosity. For isotropic turbulence, the dissipation rate $\varepsilon$ can be estimated from the energy density $E$ at each wavenumber $k$ in the inertial range:

$$
\varepsilon=\left(3.6 E k^{5 / 3}\right)^{3 / 2}
$$

As an example, the estimated dissipation rates for the 2min turbulence-run data shown in Figure 10 (Flight 556, Run 29) is shown in figure 12 as function of wavenumber. Nearly constant levels of dissipation rates can be observed for wavenumbers between 0.003 and 0.3 (wingtip boom sensors). Table 4 summarizes the range of dissipation rates for these wavenumbers computed for the turbulence runs of each of the six flights. The dissipation categories as described by MacCready [7] are included in Table 4 to characterize ambient atmospheric turbulence. Using these categories, the ambient turbulence levels encountered in the tests varied between "moderate" and "negligible". This characterization based on dissipation rate is in agreement with qualitative reports of turbulence levels given by the OV-10 pilots in the present flights.

The overall wake development (such as distance needed for onset of Crow instability growth) as summarized in Table 3 appears to correlate with the level of atmospheric turbulence.

Local Variations in Ambient Turbulence - Preliminary analysis of the video data obtained from the "encounter runs" indicates that rather large local variations in the wake shape (i.e., amplitude of apparent Crow oscillation) can occur in a short period of time as the OV-10 trails the C-130.
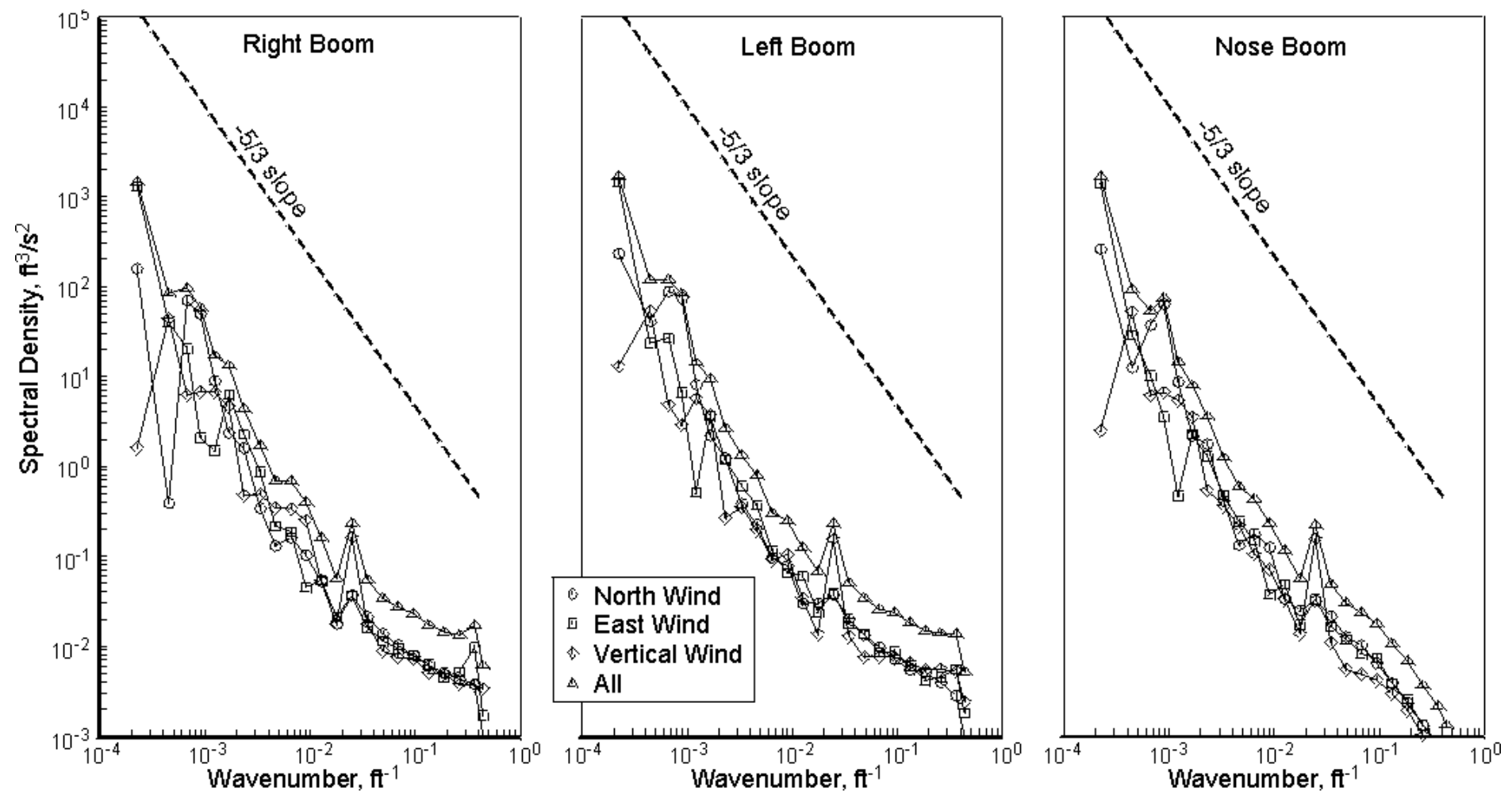

Figure 11. Spectral density from 2 minute "turbulence" run (Flight 705, Run 25). 
As an example, results from Flight 558, Run 28 with the OV-10 flying encounters at about 1.8 nautical miles behind the $\mathrm{C}-130$ are discussed. The wake was fairly straight and steady at the beginning of the run, but quickly became wavy and oscillatory, both vertically and horizontally, at a short time thereafter. This occurred over approximately 1 minute and 10 seconds. The OV-10 had flown a maneuver at the beginning of the run near the wake, but outside its influence, supplying 10 seconds of clean data. Another 10 seconds of measurements outside the wake are also available between two encounters (encounters 4 and 5) later in the run. The spectral content of the velocity perturbations for these samples are shown in Figure 13, together with the data for "turbulence" Run 25. The left most plot is the 10 seconds at the beginning of the run, the middle plot is near the end of the run, and the right plot is the nearest 2-minute turbulence run. The 10-sec data window allows only reduced wavenumber resolution as compared to the 2-min turbulence run. However, the fact that the "-5/3 Kolmogorov" slope is clearly observed also in the 10 -sec data sets allows direct extrapolation to smaller wavenumbers in the range of the Crow wavelength. As noted above, for the altitude range of this flight test, the Crow wavelength is within or close to the inertial wavenumber range.

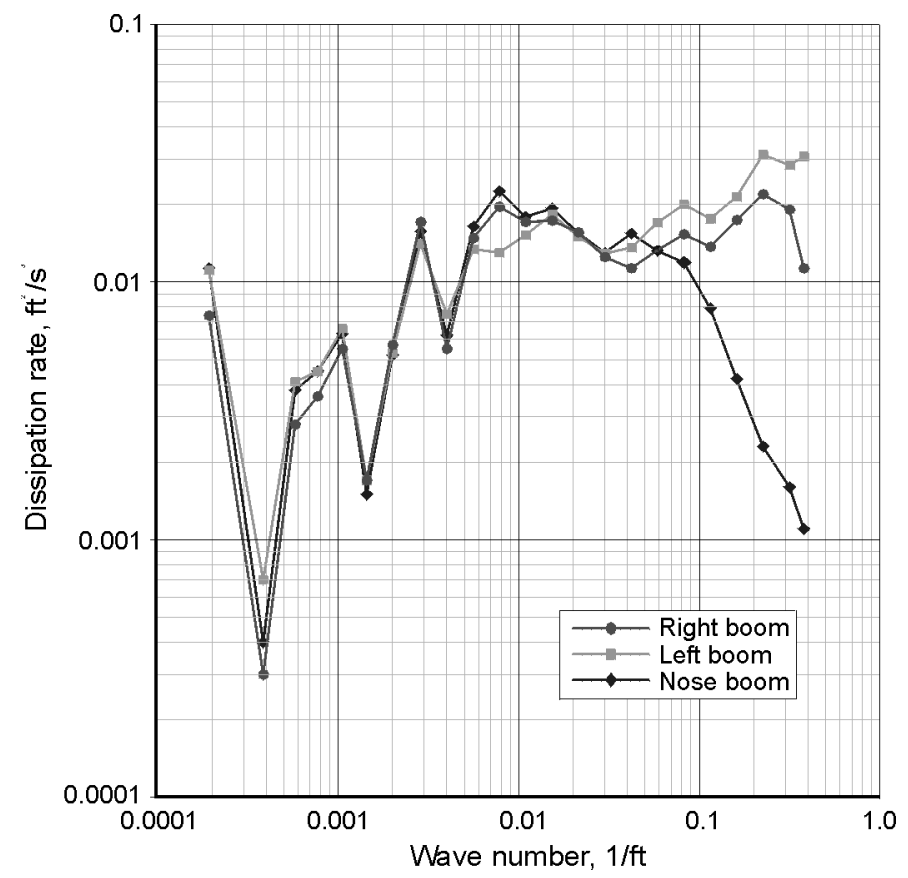

Figure 12. Turbulent dissipation rate (Flight 556, Run 29).
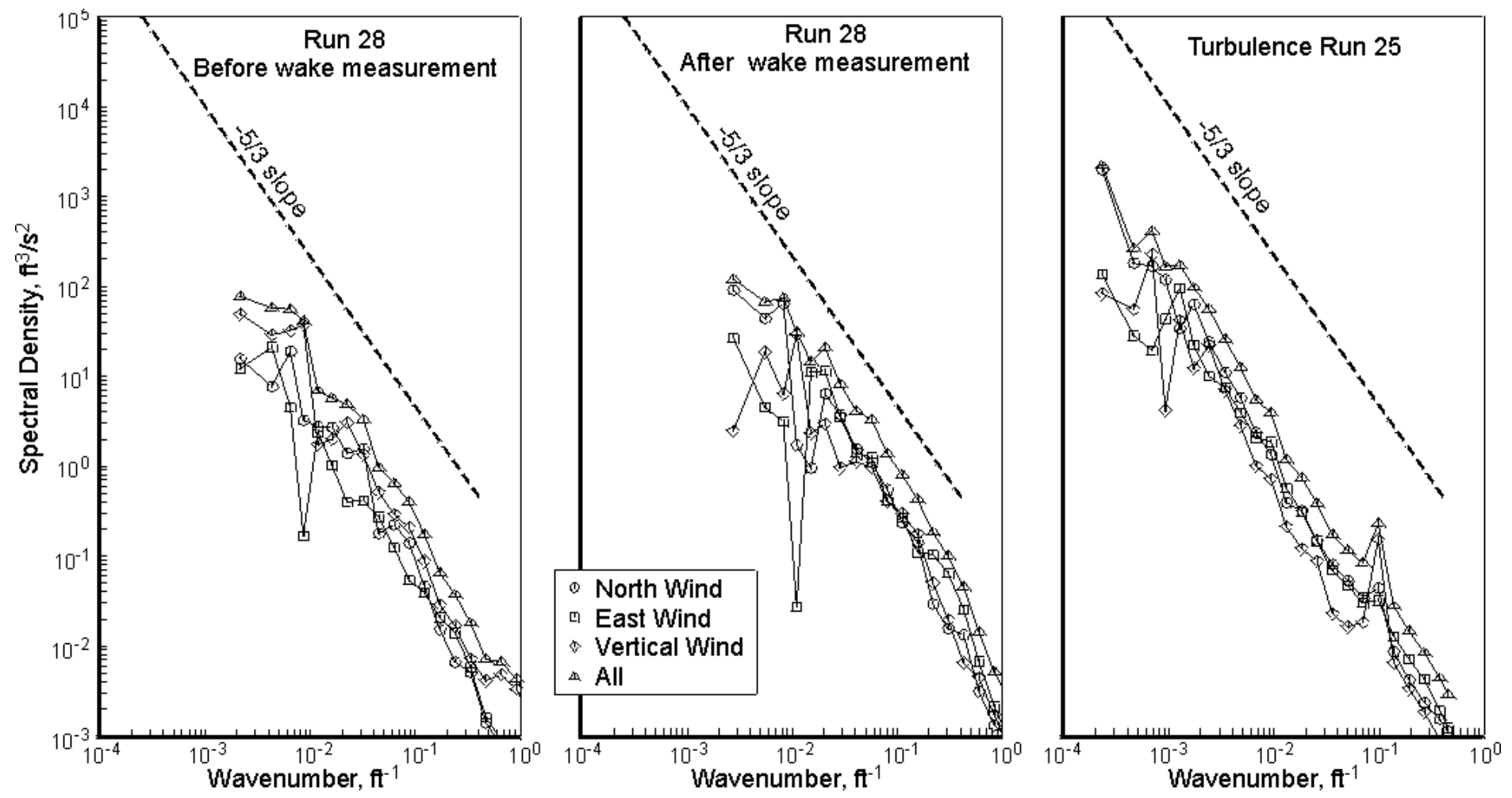

Figure 13. Comparison of local and ambient spectral density data (Flight 558, Run 25 and 28, Nose boom data). 
Comparison of the plots in Fig. 13 for the encounter runs shows an order of magnitude increase in turbulent energy levels for resolved wavenumbers (i.e., 0.05) between the two 10-sec data segments. In other words, the measured change in local ambient turbulence correlates with apparent locally increased Crow amplification and highly oscillatory wake shape as observed in the video data. The viscous dissipation rate obtained from short data sets (i.e., on the order of several seconds) at rather high wavenumbers can be useful to characterize ambient turbulence levels at scales relevant to Crow instability. Proper sensors (e.g., vanes) and aircraft instrumentation (e.g. inertial and GPS navigation systems as installed in the OV-10), combined with appropriate data-analysis routines, may allow useful qualitative turbulence measurements towards in-situ prediction of aspects of wake development.

During Flight 705, short rectilinear flight segments were included to allow sufficient data sets for characterization of possible local ambient turbulence levels. The very low level of turbulence in this flight (see Table 4), however, may preclude detection of quantifiable differences in ambient turbulence levels during an encounter run.

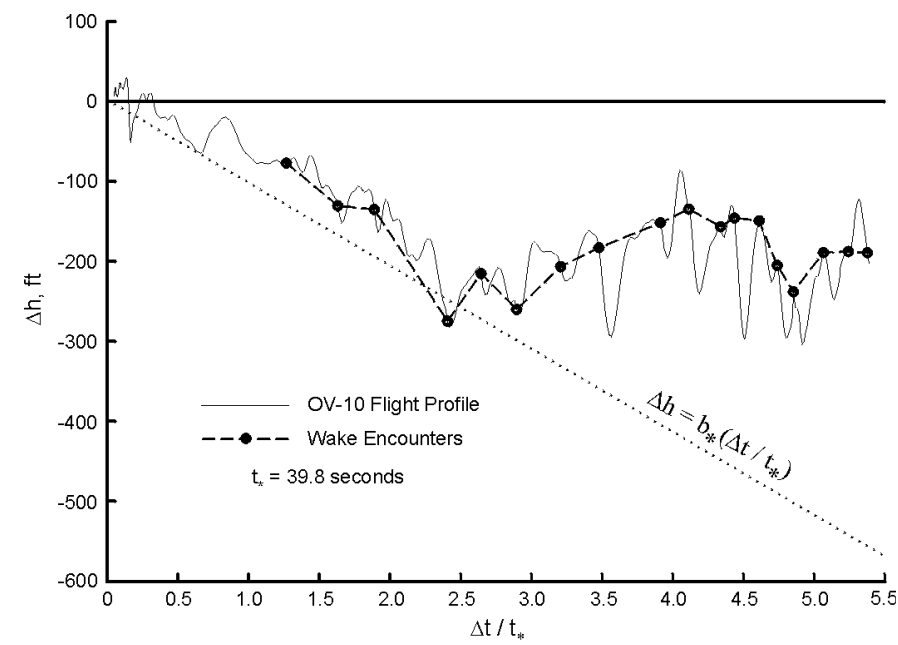

Figure 14. OV-10 measured wake descent of a C-130 (Run 26, Flight 558).

In summary, the OV-10 nose and tip-boom instrumentation and data-reduction system allows quantitative characterization of ambient atmospheric turbulence during the dedicated "turbulence" runs as well as during time windows from the "encounter" runs away from the wake.

WAKE DESCENT PROFILES - The vertical position of the trailing wake relative to the (constant) flight altitude of the C-130 generator aircraft is determined from each OV10 wake encounter. Figure 14 shows an example of the wake decent against non-dimensional time. During the first 2.5 time units the wake descends in a manner in fair agreement with wake circulation $\left(\Delta h=b_{*} \cdot \Delta t / t_{*}\right)$.

However, during the remaining time the wake descent is considerably different and an apparent "rebound" is observed. The apparent "rebound" of the wake may be due to local variations in the vertical wind, temperature profile (stratification), or ambient turbulence (see also Ref 3 ) as the OV-10 samples the wake in different locations of the atmosphere. Recent numerical simulations indicate that wake rebound is predicted for sufficiently strong stratification [14].

Figure 15 summarizes in a histogram the relative vertical location of the C-130 wake obtained from the OV-10 measurements at various downstream distances for a variety of C-130 airspeeds. The average wake descends as a function of the separation distance. However, there are several encounters where the wake location is at or just above the flight altitude of the C-130. In the flight with the lowest ambient turbulence (Flight 705), the wake could be observed and had measurable wake-perturbation velocities as far back as $10 \mathrm{nmi}$.

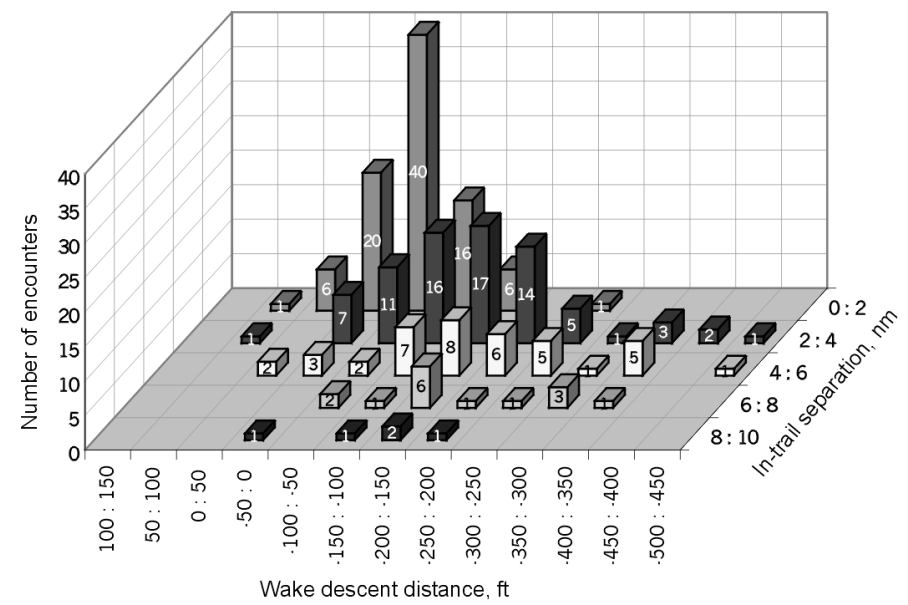

Figure 15. Histogram of wake locations (from all encounters) at various separation distances.

WAKE VORTEX VELOCITY PROFILES - The OV-10 encounters provide wake vortex velocity profiles in a reference system attached to the local wake (see Flight Data-Reduction Process section above). In total about 230 encounters are available (see Table 2).

As an example of typical measurements available, Figure $16 a$ shows the horizontal and vertical wake induced velocities corresponding to the trajectories provided in Figures 7 and 8 . The location of the vortex pair can clearly be inferred from the velocity profiles; the approximate vortex spacing is $100 \mathrm{ft}$ (i.e. close to $b^{*}$ ). Several data points are obtained in or near the core of the left vortex. As mentioned with figures 7 and 8 , the OV-10 was flying from left to right and flew very near the center of the left vortex but below the right. This was typical of most of the wake measurement passes. The encounter with the first vortex would usually push the OV-10 below the second vortex. This resulted in measurements like figure $16 \mathrm{a}$ that clearly shows the large perturbation velocities of the first vortex compared to the data from the second. 


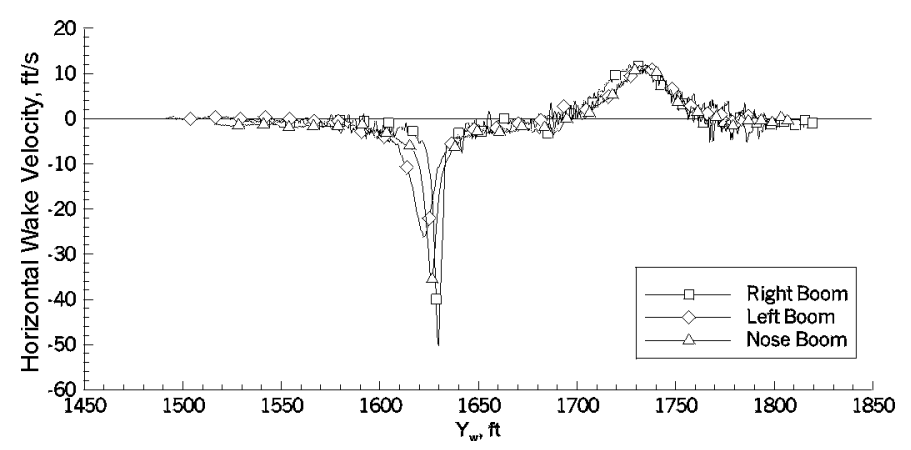

(a) Measured horizontal velocity profile (Flight 558, Run 26, Event 1).

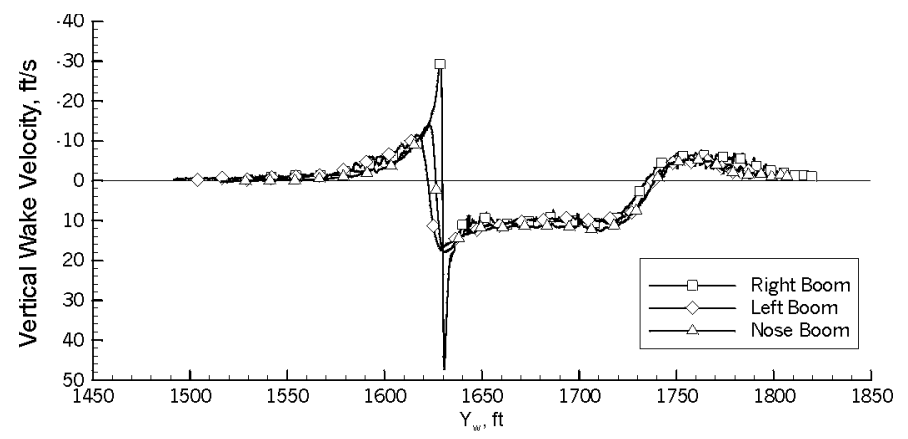

(b) Measured vertical velocity profile (Flight 558 , Run 26, Event 1).

Figure 16.

The horizontal and vertical velocities measured in the flight test can be used to evaluate analytical models for trailing-vortex flows (discussed below), and to estimate the circulation strength of the vortex pair. The measured centerline downwash velocity together with the spacing of the vortices can also provide an estimate of the strength of the trailing vortex pair.

Although not shown here, measurements of the axial velocities when a probe traversed a vortex core are available in the database.

WAKE-CIRCULATION DECAY ANALYSIS - Quantification of possible decay of circulation with wake age as function of atmospheric conditions is of interest in view of wake-prediction model systems studied for possible advanced air-traffic control [12]. In particular, flight data are of interest to evaluate aspects of "continuous-decay" and "catastrophic-event" wake-development theories (see Ref. 3).

To estimate the vortex characteristics such as circulation strength, core location, and core radius, theoretical vortex models are fit to the measured wake velocities. In this analysis a pair of independently oriented, counter-rotating, axially symmetric line vortices modeled the wake. The velocity field about each lin $V_{\theta}^{\prime \prime}(r)$ ex was represented by its tangential velocity profile $V_{\theta}(r)$, where $r$ is the perpendicular distance from the line vortex. There are a variety of vortex models that can be used for the tangential velocity profile such as a Lamb or Rankin point vortex or the vortex models proposed by Burnham [8], Hoffman and Joubert [9], or Spalart [3]. The vortex model used in this analysis was developed by the first author of this paper based on available analysis of the OV-10 measured data. The empirical model is similar to the Hoffman-Joubert and Spalart models.

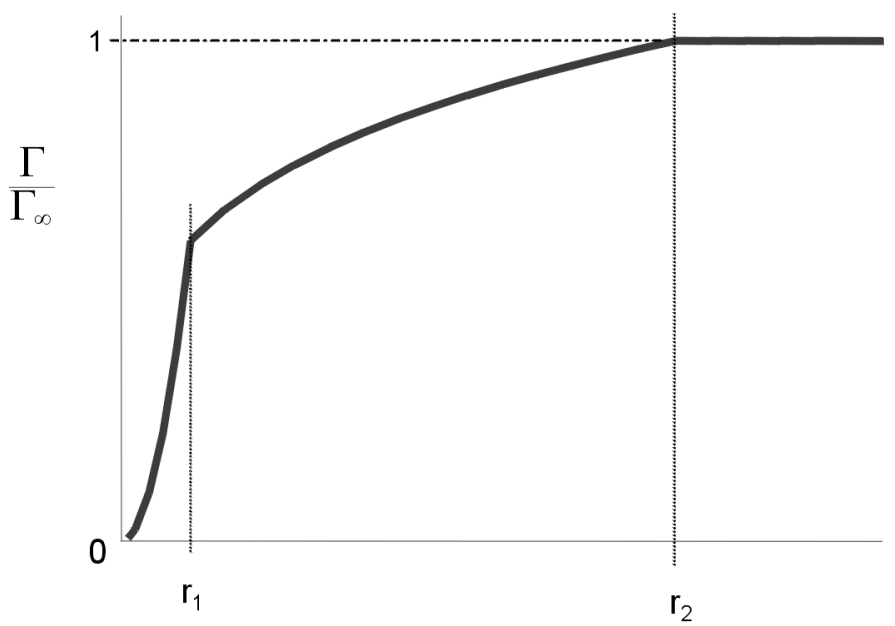

Figure 17. Vortex model circulation profile.

The vortex model used here is based on the circulation profile shown in figure 17. The circulation profile is related to tangential velocity through:

$$
V_{\theta}(r)=\frac{\Gamma_{\infty}}{2 \pi r} \frac{\Gamma(r)}{\Gamma_{\infty}}
$$

The model circulation profile is defined as:

$$
\frac{\Gamma(r)}{\Gamma_{\infty}}= \begin{cases}A r^{2} & , r \leq r_{1} \\ \left(\frac{r}{r_{2}}\right)^{a} & , r_{1}<r \leq r_{2} \\ 1 & , r>r_{2}\end{cases}
$$

where:

$$
a=\frac{2 \ln r_{1}+\ln A}{\ln r_{1}-\ln r_{2}}
$$

and

$$
V_{\theta_{\max }}=V_{\theta}\left(r_{1}\right)=A r_{1} \frac{\Gamma_{\infty}}{2 \pi}
$$

with the constraints:

$$
\begin{gathered}
0<r_{1}<r_{2} \\
0<A \leq r_{1}^{-2}
\end{gathered}
$$


For each wake measurement a multi-variable search is conducted to determine the location and orientation of the line vortex pair and the values of the vortex model parameters $\left(r_{1}, r_{2}, \Gamma_{\infty}, A\right)$ that best fit the measured data.

Figure 18a shows the measured vertical and horizontal velocity data and the model fit results for flight 558 run 26, event 1 (corresponding to figures 7 and 8).

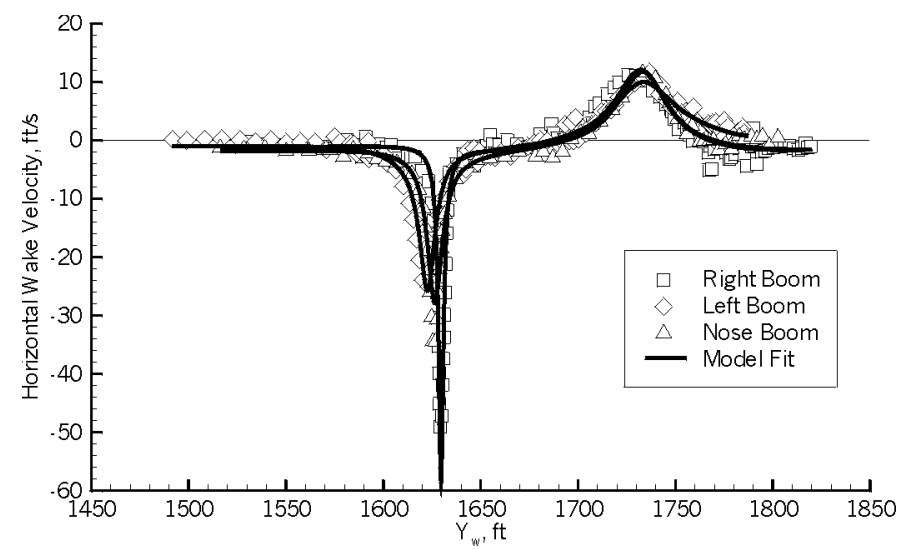

(a) Measured and modeled horizontal velocity profile (Flight 558, Run 26, Event 1).

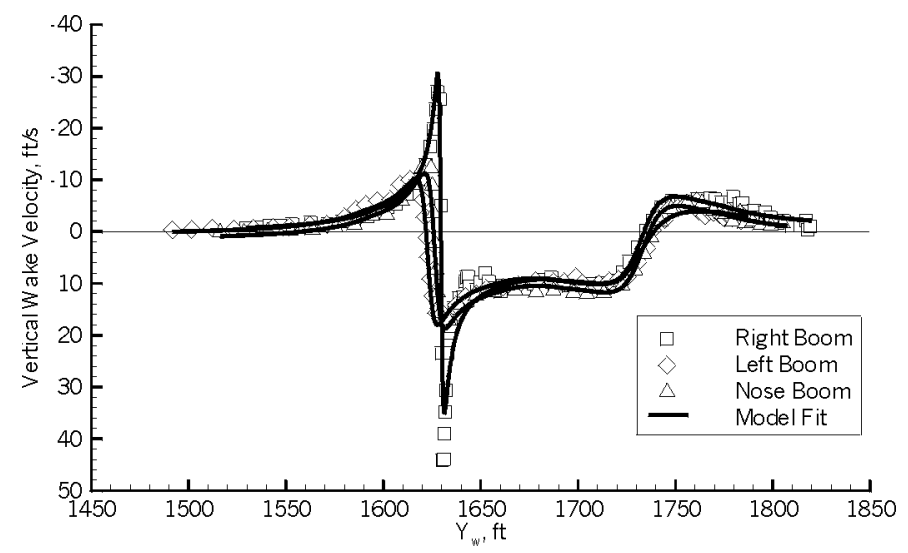

(b) Measured and modeled vertical velocity profile (Flight 558, Run 26, Event 1).

Figure 18.

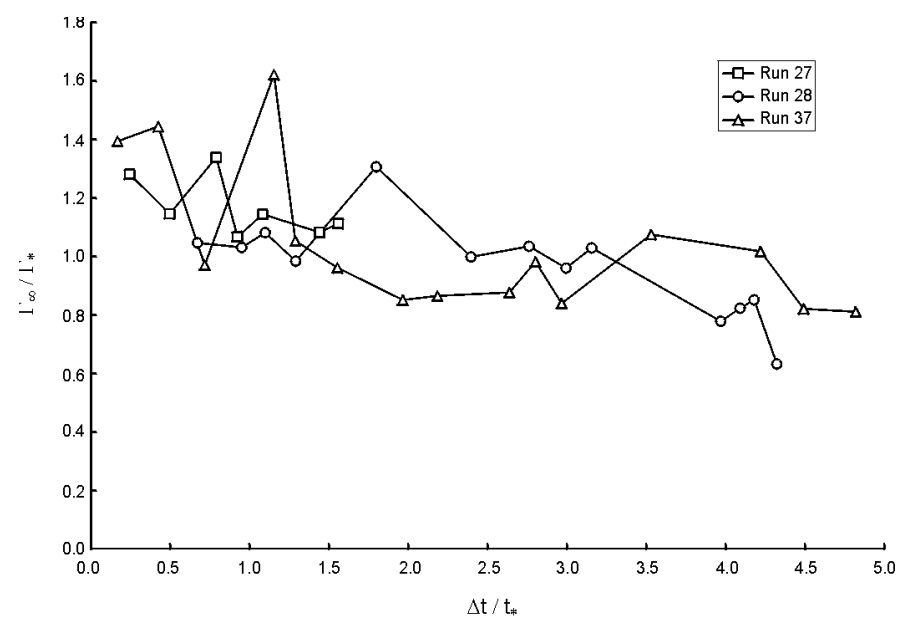

Figure 19. Nondimensional wake development obtained from model fit (Flight 705).

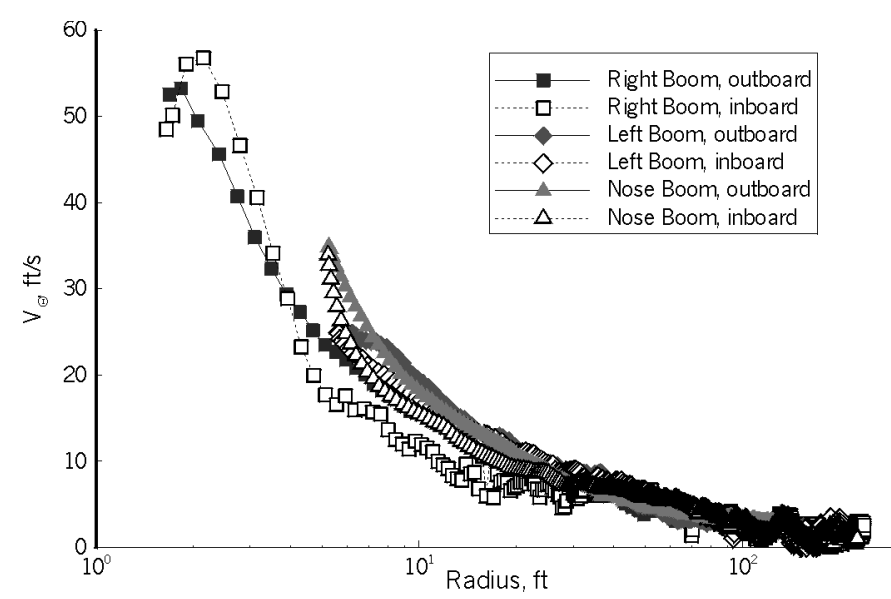

Figure 20. Left vortex tangential velocity profile (Flight 558, Run 26, Event 1).

Compiling available model-fit results as a function of (non-dimensional) wake age for a given measurement run can provide a characterization of wake development and possible wake decay. Figure 19 shows the wake decay trend for three wake measurement runs of Flight 705. Large values and variations in the circulation relative to the initial level (see Table 1) are noticeable for nondimensional wake-age values up to about 1.5. Run 27 has measurements only up to an age of 2 . A simple linear fit of the data provides a nondimensional decay rate of $0.127,-0.091$ and -0.104 for Runs 27, 28 and 37 respectively, or approximately $10 \%$ per nondimensional time unit. Run 37 however, has a nearly constant strength from 2.0 to 5.0 time units (i.e., corresponding to a separation distance of almost $10 \mathrm{nmi}$ at the C-130's airspeed).

A second method to compute circulation strength was employed for comparison with the model fit values and ground-based wake-vortex field measurements. A 3 to 10 meter spatial average of the measured single-vortex circulation, as recently proposed by Hinton and Tatnall $[10,11]$, was computed.

$$
\Gamma_{3,10}=\frac{1}{22.97} \int_{9.84}^{32.81} \Gamma(r) d r \quad\left(\mathrm{ft}^{2} / \mathrm{s}\right)
$$

This required the velocity contribution from the second vortex be subtracted from the measured wake velocity to obtain a single vortex measurement. This was accomplished by subtracting the model-fit derived second-vortex velocity contribution from the measured data. An example of the resultant single vortex rotational velocity and circulation profile are shown in figures 20 and 21, respectively, for Flight 558, Run 26, Event 1. The figures show the data from all three booms. The terms "inboard" and "outboard" refer to the single-vortex measurement location relative to the wake. For example, when measuring the left vortex, the inboard side would be on the right and the outboard side the left. The inboard measurement is more sensitive to errors in the model fit of the opposite vortex. 


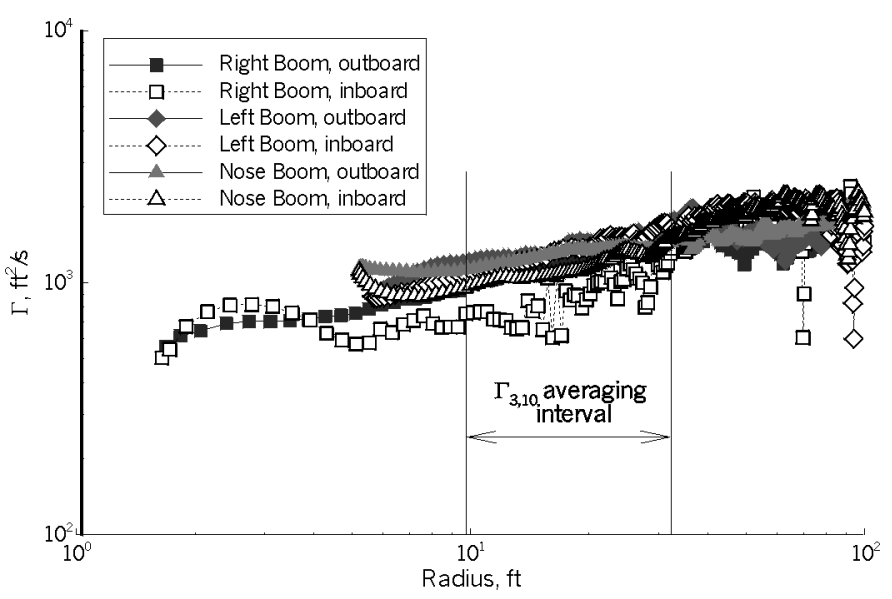

Figure 21. Left vortex circulation profile (Flight 558, Run 26, Event 1).

Figure 22 shows the nondimensional 3-10 meter averaged circulation development for Runs 27, 28 and 37 of Flight 705 . The figure shows a development trend similar to Figure 19, but with reduced variations between sequential measurements, particularly for nondimensional age less than 1.5. Note that the averaged circulation as computed here is less sensitive to the curve-fit modeling errors, resulting in less variation within and between the runs. It also shows a very low decay rate. A linear fit through the average circulation yields a nondimensional decay rate of $-0.089,-0.025$ and -0.015 for Runs 27, 28 and 37 respectively. The figure also distinguishes between the left and right vortex but show no definitive difference.

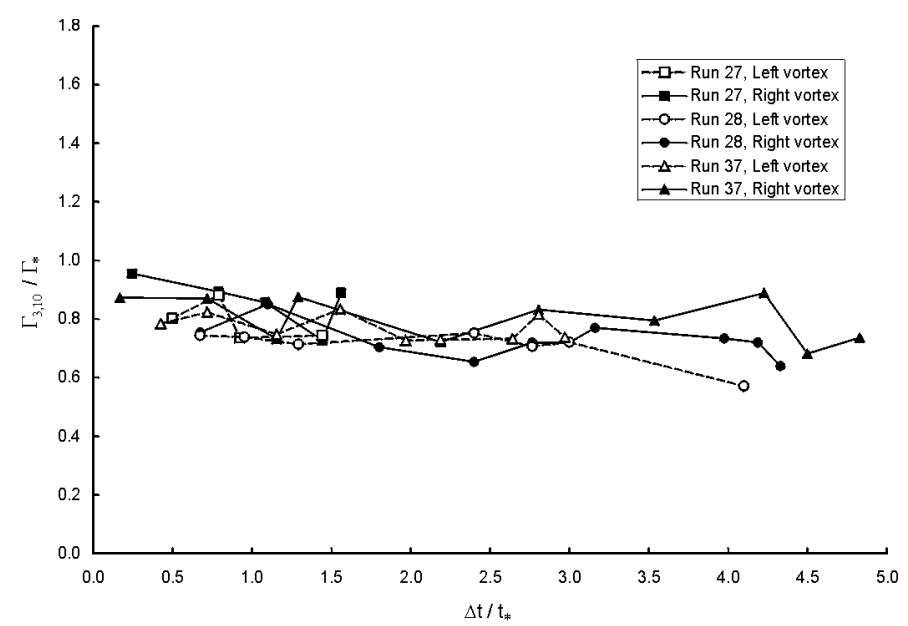

Figure 22. Nondimensionalized wake decay from 3 to 10 meter average of the 3 booms (Flight 705).

Both analysis approaches show the wake decay trend up to the highest non-dimensional wake age (corresponding to a separation distance of almost $10 \mathrm{nmi}$ at the C-130's airspeed) for a flight with extremely low ambient turbulence. Uncertainty analysis of the measured data is underway and will be included in the published database.

\section{CONCLUDING REMARKS}

Using the uniquely instrumented OV-10A research aircraft, NASA recently conducted flight tests towards characterization of trailing vortex wake development and ambient atmospheric conditions. A total of about 230 wake encounters (penetrations) at different atmospheric conditions are available at different initial-wake circulation levels.

An integrated database has been compiled that combines relevant reduced dimensional and nondimensional flight data at appropriate data rates needed for wakecharacterization analysis. In-situ and weather-balloon atmospheric data are included in the database, as well as frames obtained from video recordings of the wake shape.

Some wake-characterization analysis results are presented in this paper to illustrate the possible uses for the data contained in the database. Some observations can be made based on the preliminary analyses presented:

- Ambient-turbulence measurements obtained with the OV-10 show that the inertial turbulence range is well resolved and includes wavenumbers corresponding to most unstable wavelengths of the Crow instability.

- Computed ambient turbulence kinetic energy (TKE) levels and dissipation rates appear to correlate with the wake development (i.e., onset of Crow instability as viewed from video images) and the pilots' descriptions.

- The trailing single-pair wake generally shows a continuous descent as a function of wake age. However, several cases where the wake 'rebounds' to the flight altitude of the generator aircraft are observed.

- Wake strength (circulation) development can be obtained from the available data sets. Results obtained from curve-fitting a newly formulated vortexcirculation profile model for a flight with extremely low ambient turbulence allowed estimation of wake circulation up to a non-dimensional wake age of about 4 , with almost no decay.

Additional comprehensive analyses of data contained in the database, including further correlation with available weather data are needed for characterization of the present wake-vortex flight tests.

\section{ACKNOWLEDGMENT}

Efforts by the Boeing Commercial Airplane Group (database compilation and aspects of turbulence and wakedevelopment analysis) were supported under NASA Contract NAS1-20267 (Task 21). 


\section{REFERENCES}

1. Perry, R. B.; Hinton, D. A.; and Stuever, R. A.: "NASA Wake Vortex Research for Aircraft Spacing," AIAA 97-0057, 35th Aerospace Sciences Meeting \& Exhibit, Reno, NV, January 9-10, 1997.

2. Blake, W. B., "Development of the C-17 Formation Airdrop Element Geometry," J. Aircraft, Vol. 35, No. 2, March-April 1998.

3. Spalart, P. R.: "Airplane Trailing Vortices," Annual Review of Fluid Mechanics, Vol. 30, pp. 107-138, 1998.

4. Sarpkaya, T.: Decay of Wake Vortices of Large Aircraft, AIAA 98-0592, 36th Aerospace Sciences Meeting \& Exhibit, Reno, NV, January 12-15, 1998.

5. Stuever, R. A.; Stewart, E. C.; and Rivers, R. A.: "Overview of the Preparation and Use of an OV-10 Aircraft for Wake Vortex Flight Experiments," AIAA 95-3935, September 1995.

6. Zak, J. A. and Rodgers, W. G.: Documentation of Atmospheric Conditions During Observed Rising Aircraft Wakes, NASA CR-4767, April 1997.

7. MacCready, P. B. Jr., "Standardization of Gustiness Values from Aircraft," Journal of Applied Meteorology, Vol. 2, pp. 439-449.

8. Hallock, J. N.: "Aircraft Wake Vortices: An Assessment of the Current Situation," DOT-FAA-RD-90-29, January 1991.

9. Hoffman, E. R. and Joubert, P. N.: "Turbulent Line Vortices," J. Fluid Mech., Vol. 16, Part 3, pp. 395-411, July 1963.

10. Hinton, D. A. and Tatnall, C. R.: "A Candidate Wake Vortex Strength Definition for Application to the NASA Aircraft Vortex Spacing System (AVOSS)," NASA TM-110343, September 1997.

11. Tatnall, C. R.: "An Investigation of Candidate Sensor Observable Wake Vortex Strength Parameters for the NASA Aircraft Vortex Spacing System (AVOSS)," NASA CR-1998-206933, March 1998.

12. Hinton, D. .A.: "An Aircraft Vortex Spacing System (AVOSS) For Dynamical Wake Vortex Spacing Criteria," AGARD 78th Fluid Dynamics Panel Meeting and Symposium on the Characterization \& Modification of Wakes from Lifting Vehicles in Fluids, Trondheim, Norway, AGARD CP. 584, Paper 23, May 20-23, 1996.

13. Donaldson, C. duP. and Bilanin, A. J., "Vortex Wakes of Conventional Aircraft," AGARDograph No. 204, May 1975.

14. Spalart, P. R.: "On the Motion of Laminar Wing Wakes in a Stratified Fluid," J. Fluid Mech., Vol. 327, pp. 139-160, Nov. 1996.

\section{NOMENCLATURE}

$a:$ vortex model variable (eq. 8 )

$A$ : vortex model parameter, $1 / \mathrm{ft}^{2}$

$b$ : wing span, $\mathrm{ft}$

$b_{*}$ : initial vortex spacing, $\mathrm{ft}$

$E:$ spectral density, $\mathrm{ft}^{3} / \mathrm{s}^{2}$

$k$ : wavenumber, $1 / \mathrm{ft}$

$r:$ radius, $\mathrm{ft}$

$r_{1}$ : vortex model parameter, $\mathrm{ft}$

$r_{2}$ : vortex model parameter, $\mathrm{ft}$

$t_{o}$ : time when wake generated, sec

$t_{\text {ref }}:$ time when wake measured, sec

$t_{*}:$ time scale, sec

TKE: turbulent kinetic energy, $\mathrm{ft}^{2} / \mathrm{s}^{2}$

$V_{t}:$ true airspeed, $\mathrm{ft} / \mathrm{s}$

$u$ : longitudinal wind component, $\mathrm{ft} / \mathrm{s}$

$v$ : lateral wind component, $\mathrm{ft} / \mathrm{s}$

$V_{*}:$ initial wake descent, $\mathrm{ft} / \mathrm{s}$

$V_{\theta}:$ vortex tangential velocity, $\mathrm{ft} / \mathrm{s}$

$V_{\theta_{\max }}:$ maximum tangential velocity, $\mathrm{ft} / \mathrm{s}$

$w:$ vertical wind component, $\mathrm{ft} / \mathrm{s}$

W: weight, lbs

$X_{w}$ : longitudinal wake axis coordinate, $\mathrm{ft}$

$Y_{w}$ : lateral wake axis coordinate, $\mathrm{ft}$

$Z_{w}$ : vertical wake axis coordinate, $\mathrm{ft}$

$\Delta h$ : change in wake height, $\mathrm{ft}$

$\Delta t:$ wake age, sec

$\varepsilon$ : eddy dissipation rate, $\mathrm{ft}^{2} / \mathrm{s}^{3}$

$\rho$ : air density, slugs $/ \mathrm{ft}^{3}$

$\Gamma$ : vortex circulation, $\mathrm{ft}^{2} / \mathrm{s}$

$\Gamma_{3,10}: 3$ to 10 meter average circulation, $\mathrm{ft}^{2} / \mathrm{s}$

$\Gamma_{*}:$ initial circulation, $\mathrm{ft}^{2} / \mathrm{s}$

$\Gamma_{\infty}$ : vortex model total circulation, $\mathrm{ft}^{2} / \mathrm{s}$

$\sigma_{u}$ : standard deviation of longitudinal wind component, $\mathrm{ft} / \mathrm{s}$

$\sigma_{v}:$ standard deviation of lateral wind component, $\mathrm{ft} / \mathrm{s}$

$\sigma_{w}$ : standard deviation of vertical wind component, $\mathrm{ft} / \mathrm{s}$ 